\title{
The Leaching Paradox and Return Flow Management Options for Sustainable Irrigated Agriculture
}

\section{R J Armour and M F Viljoen}

Department of Agricultural Economics, University of the Free State

\section{ABSTRACT}

Leaching is necessary to maintain an acceptable salt balance in the root-zone of irrigated crops. This however contributes to point and non-point source water pollution externalities if not managed correctly. The use of a linear programming model, SALMOD (Salinity and Leaching Model for Optimal Irrigation Development) is demonstrated to determine the feasibility of leaching, artificial drainage, and on-farm storage/evaporation ponds to manage degraded return flows entering the water source and groundwater. Results show optimal cropping compositions and management practices to maximise farm returns subject to water quality conditions and return flow constraints. The economic effects of constraining return-flows and of water pricing policy on the volume of return flows are also determined. Results show valuable policy information regarding the interactions between artificial drainage subsidisation, return flow restrictions and on-farm storage.

JEL Q00, Q25

\section{INTRODUCTION}

With Sub-Saharan Africa having by far the highest population growth rate in the world (2.9 per cent per annum), the imminent threat of HIV/AIDS that's crippling the workforce, weather changes brought about by global climate change and the drastic slump in the regional economy, food shortages in this region loom in the not too distant future. In Sub-Saharan Africa the potential irrigable area is estimated at 33 million hectares. Presently only 13 per cent of this irrigable area is utilised for crop production. With the stability of production and increased yields offered by irrigation, tremendous pressure is going to be placed on expanding the potentially irrigated area in Sub-Saharan Africa. This will be at a disastrous cost to the environment and hence on the sustainability of new and existing schemes if the necessary precautions are not taken. 
In a study by Seckler et al. (1999) titled Water Scarcity in the Twentieth Century, South Africa is classified under category 1: "These countries face 'absolute water scarcity'. They will not be able to meet water needs in the year 2025." Water use efficiency in irrigation agriculture will thus also become crucial as per capita demand for water increases (Basson et al., 1997). "There are (also) clear indications, ... , that the price of water for all uses including irrigation will be adjusted upwards to better reflect the cost of supply or perhaps even its value" (Backeberg et al., 1996: 12).

Backeberg et al. (1996: 22), further states that "water quality is becoming of increasing concern to irrigation, both from a supply point of view and with respect to the environmental impacts of irrigation." In 1995 in South Africa alone about 110000 hectares of irrigated land were already affected by waterlogging and/or salinisation. Currently irrigation in Sub-Saharan Africa is by far the largest user of stored water, using 83 per cent, and in South Africa 53 per cent (Backeberg et al., 1996). With total water demand expected to exceed supply before 2020 , industry and urban users are going to be competing strongly for this valuable resource. The price-cost squeeze experienced by farmers over the last few decades, the weakening terms of trade, recent drastic fuel price increases and the increasing cost of labour further jeopardise the economic sustainability of irrigation agriculture, an industry so crucial for the economies of many rural areas.

A major factor that could possibly further jeopardise the sustainability of irrigated agricuiture, but which can be effectively controlled, is the accumulation of minerals salts in irrigated soils, which results in a breakdown of soil structure and accumulate to levels toxic to the crops grown. According to Gouws et al. (1998: 8) the three water quality components that have a financial impact on crop production are the "total salt effect, specific ion toxicity and sodium effect on soil properties". The concentration of dissolved salts, be it from natural or anthropogenic causes, currently poses the greatest threat within the study area. "The rise and fall of a number of past civilizations have been linked to their ability to sustain irrigated agriculture. The inability to control salinisation and degradation of irrigated lands are mostly viewed as the main causes for their decline" (DWAF, 1993).

No itrigation system is sustainable without sufficient drainage. Unless natural drainage till below the root zone is sufficient and water tables are not rising, artificial drainage has to be installed. According to Du Preez et al. (2000: 154) "Results from these estimations (Szabolcs model) indicate that all the undrained soils will, due to excessive salt accumulation, become unsuitable for irrigation by approximately the year 2050." To reinforce this, Brady and Weil (1996: 307) state that "if the irrigation system does not provide good internal drainage, soil 
salinity can increase to intolerable levels, as can the exchangeable sodium level. The latter engenders chemical and physical problems that, if not corrected, will render a soil virtually useless as a habitat for plants."

Leaching is the process of applying water over and above the requirements of the plants irrigated. It is a management practice used to "flush" a certain amount of accumulated saits out of the root zone to maintain an acceptable salt balance. This practice is often considered by non-specialists as wasteful, especially as irrigation engineers and scientists appear to be in doubt about the required leaching rates and the efficiency of the leaching practice (Kijne et al., 1998).

To leach effectively, soils should have a good infiltration rate till beyond the root zone. In heavy soils and where waterlogging occurs, artificial drainage is required. The heavier the soils, the more expensive the costs of installing the artificial drainage. Thus the benefits of leaching need to be quantified to be able to justify the capital expenses involved.

Leachate flows back into the river or groundwater carrying high concentrations of salts, further degrading the water source and creating secondary costs through externalities for downstream users. The paradox, however, is that without leaching salts (those inherently found in soil or those deposited by irrigating with poor water quality) out of the soil, salts build up, degrading the soil to levels that can no longer support viable crop production. Improper leachate management results in downstream water degradation, rendering it less suitable for other users, and damaging the environment. It may cause watertables to rise and flushes expensive nitrogen applied to the fields, carrying with it other agricultural chemicals.

The importance of irrigation has been stressed and leaching is essential for its long-tern sustainability. In the past, the government subsidised the installation of artificial drainages. However, subsidising drainage creates an incentive to leach more. The negative externalities created by return- flows thus need to be managed. Using SALMOD, (Salinity and Leaching Model for Optimal Irrigation Development) the economic impact of constraining return-flows is determined. Incorporating into the model an option of building an on-farm storage dam to manage return flows, also makes it possible to determine whether or not it is cost effective to build the dam.

The main purpose of SALMOD is to optimise the farm level total gross margin above specified costs (TGMASC) to ensure optimal resource use and to identify the constraints preventing the maximum TGMASC form being attained. This is achieved by calculating with linear programming the optimal crop combination for a farm's specific physical resource endowment, subject to various 
constraints. Particularly useful data generated by the SALMOD, are the dual or shadow values of the constraints. These values indicate how much can be paid for one extra unit of a constraining factor, for example how much can be paid for one extra $\mathrm{mm} / \mathrm{ha}$ on top of the existing quota for irrigation water.

Figure 1 A schematic representation of the positioning of the OVIB study area within the regional bydrology

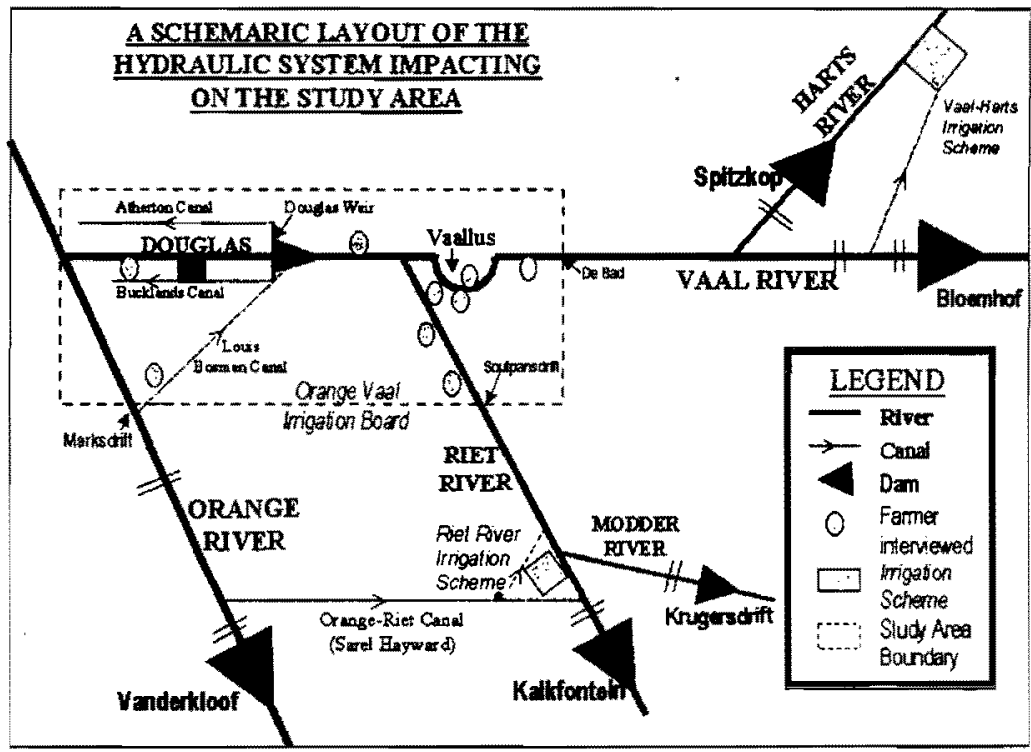

\section{THE STUDY AREA}

Douglas, the main town within the study area (see Figure 1), is a thriving community based entirely on the forward and backward linkages of the irrigation industry. The initial Bucklands and Atherton irrigation plots allocated were part of a government social-economic scheme after the drought and depression of the 1930s (DWAF, 1993: 14). The sustainability of the soils on which these plots were established for irrigation agriculture was not a primary factor as they were developed mainly for socio-economic purposes.

In 1984 an Irrigation Board was established to manage water allocations in the demarcated area. Currently water is charged for on a per hectare basis and not on a volumetric basis, which distorts incentives for efficiency in irrigation water application. 
Figure 2 Salinity fluctuations measured as EC(mS/m) and $\mathrm{TDS}(\mathrm{mg} / \mathrm{l})$ at the Douglas Barrage on the Vaal River, DWAF 1977-1997

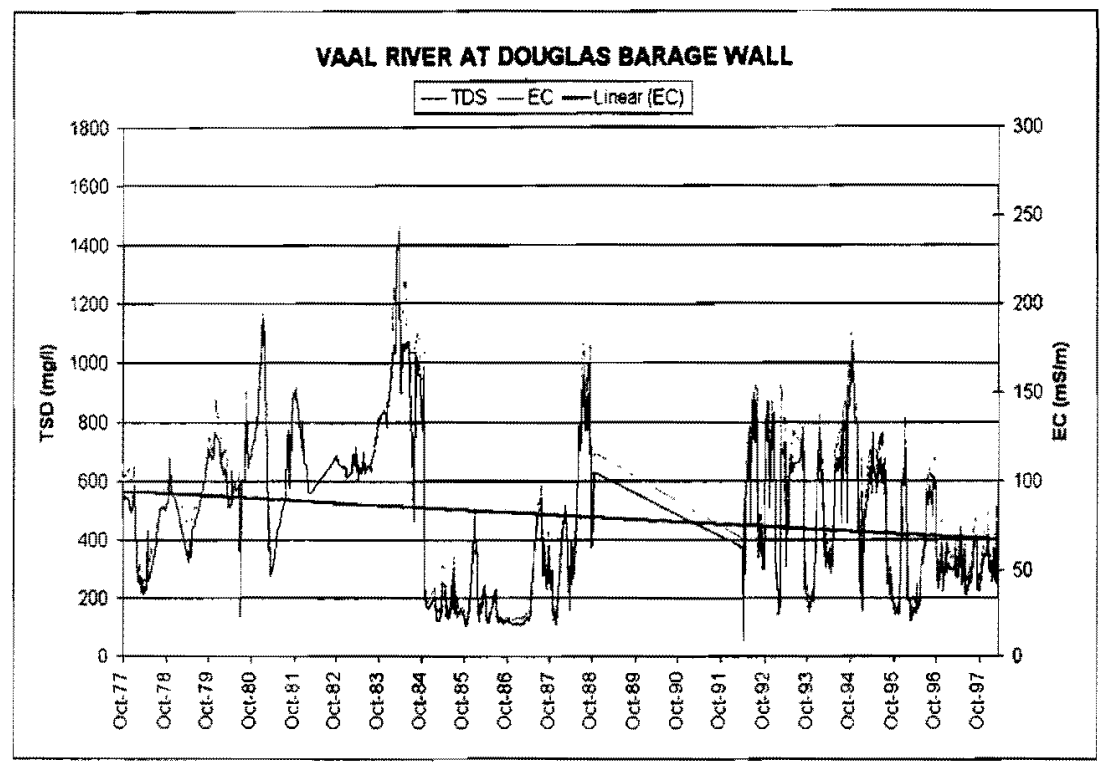

Being right at the bottom of the Vaal River system, water usage was usually prioritised for industrial and residential use in Johannesburg and for mining purposes in the Free State goldfields. During times of drought in the upper catchment, this would lead to water shortages in the study area. A particularly bad drought from 1982 led to the construction of a canal in 1984 to transfer Orange River water to the Douglas weir. Together with the increased water security, farmers noticed a marked improvement in crop yields due to the improvement in water quality. Water quality improved dramatically after Orange River water was pumped into the system via the canal as can be seen in Figure 2 after 1984.

The reason for the poor water quality was initially believed to be the result of industry and mining in the upper reaches of the Vaal River. It has since been proved by various studies (Du Plessis, 1982; Moolman \& Quibell, 1995; Nell, 1995) that the actual process of irrigation displaces certain salts in the soil and releases sodium, chloride and other salts into the water while at the same time breaking down the physical structure of the soil. This salinity problem together 
with the current "price-cost squeeze" effect has led to the questioning of the long-term sustainability of current irrigation practices in the OVIB region.

The price currently charged for irrigation water in the OVIB region is far below that paid by industry and municipal users. Farmers are also not accountable for the degraded return flows coming off their lands. The National Water Act of 1998 however addresses these issues and hence the need for functional models to help guide policy in the right direction, as well as to prepare farmers for the possible impacts of various scenarios.

Pumping is one of the largest cost items in irrigation due to high energy costs, resulting in farmers being reluctant to intentionally "over-irrigate" to leach out salts that have built up in the soils after years of irrigation. However, with the irrigation quota being based on a volume per hectare water right basis and not a volumetric basis, farmers who over-irrigate are not accountable for it. Because the river operates within a closed system, all leachate retums into the system, exacerbating the problem. Should the problem persist, the concentration of salts could eventually lead to the total withdrawal of agricultural activity from the area. Unless a solution is found, the sustainability of this important food producing area is at stake.

The rapid fluctuation in water quality, especially in the Lower Riet River arm makes crop production highly unpredictable, leading to financial instability in the region. This has resulted in a selection of crops away from crops with the highest returns, towards crops with the most predictable returns.

\section{METHODOLOGY}

The proposed methodology uses both optimisation and simulation techniques. Negahban et al., 1997, define optimisation as "a tool which can sift through the numerous combinations of local choices to pick those which, when combined, will produce an optimum plan which best meets regional goals within the constraints imposed on combinations of activities." The use of both optimisation and simulation is motivated by ASCE (1990: 530):

One approach to select the best management practice is to simulate alternative management policies using crop-water production functions and then choose the best according to some criterion. Another approach is to formulate a dynamic optimisation problem and then solve it with the appropriate algorithms. The simulation approach allows construction of a detailed physical chemical and biological processes model but does not optimise beyond simple enumeration or trial and error. Dynamic 
optimisation finds the best management practice under specific conditions, but computational considerations usually limit model complexity. The two approaches may be combined for some applications. First, the various options are screened with an optimisation model, and then one or more simulation models are used to evaluate the selected options.

SALMOD is constructed using GAMS (Brook et al, 1997) coding in two sections. Contrary to ASCE (1990: 530), a simulation section precedes an optimisation section. The simulation section determines a range of gross margins and water requirements for all possible combinations of six crops, four soil types, four soil drainage statuses and three irrigation systems, for each of two methodologies. This results in approximately 1700 crop combination activities for SALMOD to choose from for each of the leaching fraction (LF) and yield percentage (YP) methodologies.

For the LF methodology, the electrical conductivity of the irrigation water (ECiw) first has to be converted to the electrical conductivity of the saturated soil paste (ECe), using the following formula:

$$
E C e_{c, s, d s, l f}=A_{-} E C_{-} C W_{c} \cdot W C F_{s, d s, l f}
$$

where: $A_{-} E C C_{-} W_{c}$ is the average $\mathrm{EC}$ of the crop water, weighted according to monthly volumes demanded at monthly ECiw values for each crop (c) and

$W C F_{s, d s, l f}$ is the water conversion factor from ECiw to ECe and is a three dimensional matrix of soil type $(s)$, soil drainage status $\left({ }_{d s}\right)$ and leaching fraction( $(v)$.

The key formula of the LF methodology determines the relative yield (RY) percentage over a fixed range of leaching fractions. The $R Y$ for each crop $\left(_{e}\right)$ is a function of the soil type, drainage status of the soil and leaching fraction implemented. The matrix of ECe values is then used in the LF methodology as follows:

$$
R Y_{c, s, d s, d f}=\left(\left(100-G R A D_{d}\right)^{*}\left(E C e_{c, s, d s, l f}-T R S H_{c}\right)\right) / 100
$$

where: $T R S H_{c}$ is the ECe limit for each crop $\left(_{c}\right)$ at which no crop yield reductions will be observed as water quality deteriorates as determined by Maas and Hoffman (1977), and $G R A D_{c}$ is the gradient for each crop (c), after the threshold has been reached, at which yield declines as ECe deteriorates (Maas \& Hoffman, 1977). 
The key formula of the YP methodology determines the leaching requirement (LR) percentage over a fixed range of targeted yield percentages. The formula as used in Ayres and Westcot, (1985:26) is as follows:

$$
L R_{c, y p}=A_{-} E C_{-} C W_{d} d\left(5^{*}\left(T R S H_{c, y p}-A_{-} E C_{-} C W_{d}\right)\right)
$$

where: $\quad T R S H_{c, y p}$ is a matrix of the ECe limits for each crop $(c)$ at which no crop yield reduction will be observed below the specific yield percentage as water quality deteriorates (Maas \& Hoffman, 1977), adapted to be a function of the expected yield percentage.

The shortcoming of the YP methodology is that it assumes the ECiw to ECe conversion factor constant over all soil types, drainage statuses and irrigation systems used. This is not the case; and is better captured in the LF methodology. The YP methodology is included in SALMOD because it calculates the exact leaching fraction required for a specific yield percentage target, while the LF methodology calculates the actual percentage of optimal yield attainable for a specific leaching fraction. Results from the LF methodology are shown in this paper.

The final step of the simulation section is the setting up of the range of crop/resource combination gross margin above specified costs $\left(G M A S C_{c, s, d s, i d}\right)$ to be transferred as the decision variable coefficients $\left(G M_{i}\right)$ into the optimisation section of SALMOD:

$$
G M A S C_{c, s, d s, l f}=P R I C E_{c} * M E Y_{c} * R Y_{c, s, d s, l f}-F V C_{c}-H C_{c} * R Y_{c, s, d s, l f}
$$

where: $\quad P R I C E_{c}$ is a vector of selling prices for each crop $\left(_{c}\right)$,

$M E Y_{c}$ is a vector of the maximum expected yield of each crop (c), $F V C_{c}$ is a vector of the variable per hectare production costs for each crop $(c)$ excluding the water price and pumping costs, and $H C_{c}$ is a vector of the per ton harvesting costs of each crop $(c)$ dependant on the calculated relative yield $(R Y)$.

The structure of the linear programming problem in its most basic form is as follows:

Maximise $\quad \Pi=\sum_{i=1}^{*} G M_{i}, X_{i}$

subject to

$\sum_{i=1}^{*} A_{i j}, X_{i} \geq \leq$ or $=R_{j}$

$$
\begin{aligned}
& (i=1,2, \ldots, n) \\
& (j=1,2, \ldots, m)
\end{aligned}
$$

and $\quad X_{i} \geq 0$

where: $\quad \Pi=$ Net Returns,

$G M_{i}=$ Gross margin for $\mathrm{I}=1$ to $\mathrm{n}$ activities,

$X_{i}=$ the decision variable for the $\mathrm{i}^{\text {th }}$ level of activity $(\mathrm{i}=1$ to $\mathrm{n}$ ), 
$A_{i j}=\mathrm{m} \times \mathrm{n}$ matrix of constraint coefficients, and

$R_{j}=$ the $\mathrm{j}^{\text {th }}$ constant constraint value $(\mathrm{j}=1$ to $\mathrm{m}$ ).

The objective function (5) is to maximise farm net retum ( $\Pi$ ) (or TGMASC) by choosing the optimal level of activity $(X)$ from the range of choice variables $X_{i}(i=1$ to $n)$ multiplied by the objective function coefficients $G M_{i}(i=1$ to $n)$, which are a set of constants calculated in the simulation section of the model. In equation line 6 the objective function is subject to $j(j=I$ to $\mathrm{m}$ ) constraints. The levels of these constraints, $R_{j}$ are also constants. The coefficients of the choice variables $\left(X_{i}\right)$ in the constraints are denoted by $A_{i j}$. Since there are $m$ constraints in $n$ variables, the coefficients $A_{i j}$ form a rectangular matrix with an $m \times n$ dimension. Equation line 7 is the non-negativity constraint of the choice variables. Table 1 is a schematic layout of the linear programming matrix of SALMOD in which the soil drainage and irrigation system management options are excluded as generated in GAMSCHK by McCarl (1998).

\section{RESULTS}

The results generated by SALMOD shows the following:

- The maximum attainable farm level total gross margin above specified costs (TGMASC) under various water quality and management scenarios.

- The optimal combination of leaching fraction and yield reduction management options that would attain the maximum farm level TGMASC over a production year.

- The identification of the main factors of production constraining attainment of optimal TGMASC.

- What farmers in the OVIB region can indirectly afford to pay for irrigation water of various qualities (salinities) in a free market water system.

- What the impact of various management scenarios and constraints will be on the dual or shadow value of irrigation water.

- How the crop composition in each sub-region is expected to change as water quality changes.

- What the impact of restricting irrigation retum-flows would be on the TGMASC of the various case-study farms. 
Table 1 A schematic representation of the structure of the optimisation (LP) section of the SALMOD model with a description of the constraints (soil drainage and irrigation system management options excluded)

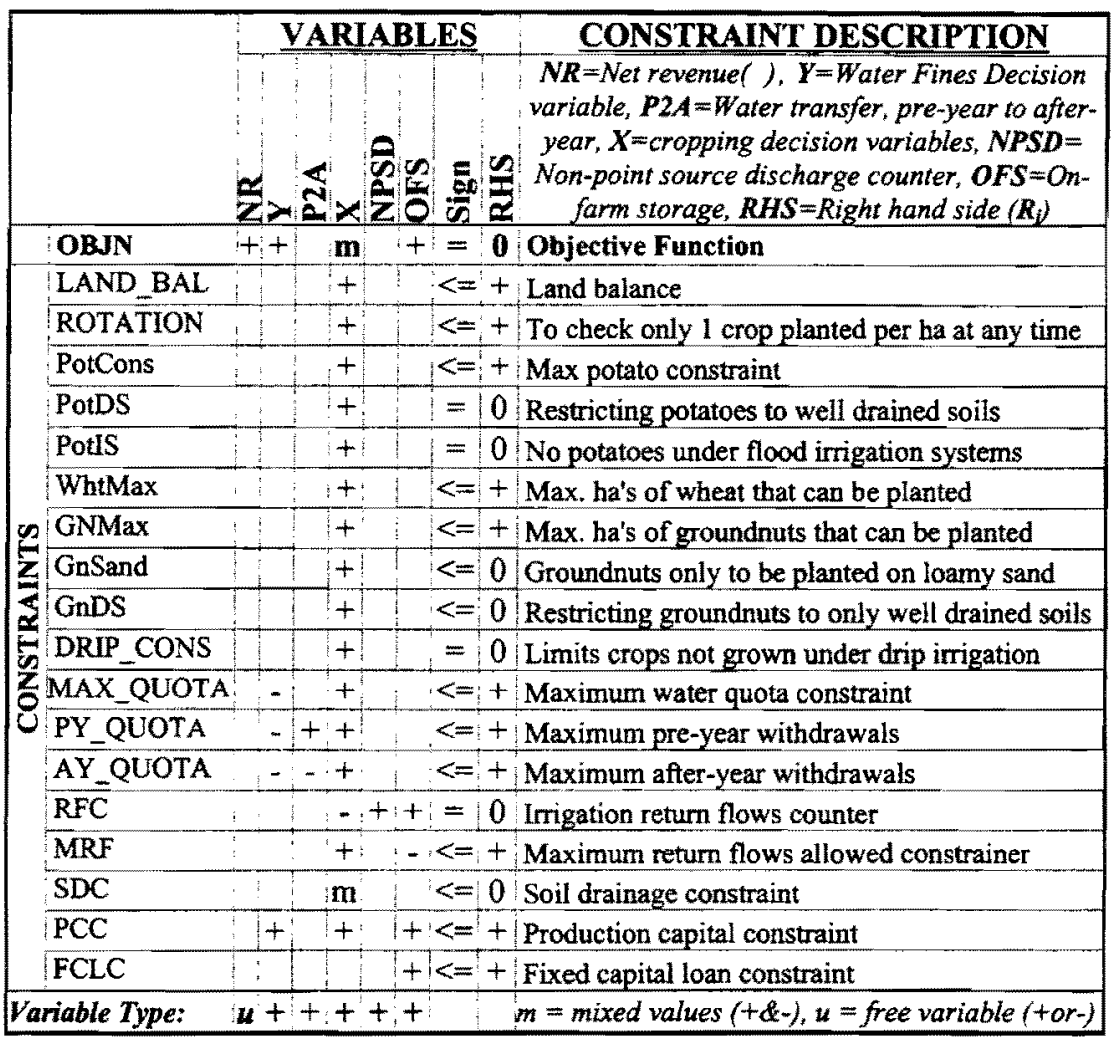

For all water quality and parameter changed scenario runs, SALMOD is run with and without fixed capital management options (the latter, no management options, is referred to as "nmo") to show the financial impact of the fixed capital management options as compared to the status quo.

The management options tested with SALMOD in this paper are as follows:

- Model implicit management options that determine the optimal combination of yield percentages and leaching fractions to use to maximise the objective function.

- Model explicit management options that test the impact of constraining the total farm irrigation return-flows allowed, production capital and the 
leaching ability of centre pivot irrigation systems on the objective function.

- Fixed capital improvement management options that entail the enhancement of the drainage status of irrigated soils, a possible change in the irrigation systems used to irrigate the crops and the option of constructing on-farm storage if irrigation retum-flows were to be constrained.

The water quality data set used to display the impact of possible water quality changes is a table comprising 10 per cent interval parametric changes from the actual monthly water quality readings taken by the OVIB for 1998 .

For the purpose of this paper, only the results for a case study farmer from Olierivier, a sub-region of the OVIB, will be analysed.

Table 2 Olierivier case-study farm basic model input data, 2000

\begin{tabular}{|l|c|}
\hline \multicolumn{2}{|c|}{ General input data } \\
\hline Irrigable area (ha) & 200 \\
\hline Imigation rights (ha) & 141 \\
\hline Water cost (R/mm/ha) & 0.17 \\
\hline Pumping costs (R/mm/ha) & 0.56 \\
\hline Pre-determined fixed costs (R) & 561000 \\
\hline
\end{tabular}

The general input data required in SALMOD to define the Olierivier case-study farm are displayed in tables 2 to 4 . The farm consists of 200 hectares of irrigable land of which only 141 hectares have an irrigation quota/right. The price of irrigation water for which SALMOD is run is the 1998 OVIB price set for the area, namely R0.17 per millimetre per hectare (mm/ha). The pumping cost used however is the average pumping cost determined in the pilot survey conducted in the area. These prices are fixed in all the scenario runs unless specified otherwise. The pre-determined fixed cost for the Olierivier case study farmer is R561 000. To determine annual net farm profit/loss, this value is subtracted from the TGMASC value generated by SALMOD. 
Table 3 The division of the Olierivier case-study farm irrigable area into soil type, irrigation system used and the drainage status of the soil (ha's), 2000

\begin{tabular}{|l|c|c|c|c|c|c|c|c|}
\hline Soil type & LMS & 190 & SNL & 10 & SNC & 0 & CLY & 0 \\
\hline Irrig.syst & FIS & 35 & CPI & 165 & DIS & 0 & & \\
\hline Drain.class & NDS & 100 & ADS & 20 & LDS & 70 & WLS & 10 \\
\hline
\end{tabular}

The soil type is a function of the clay percentage of the soil. Of the 200 hectares irrigable soil, the Olierivier case-study farmer has 190 hectares loamy sand (LMS: < 15 per cent clay), and the remaining 10 hectares are sandy loam (SNL: 15-25 per cent clay). There are no hectares sandy clay (SNC: $25-45$ per cent clay) and clayey soils (CLY: $>45$ per cent clay). 165 hectares are under a centre pivot irrigation system (CPI) while the remaining 35 hectares are flood irrigated (FIS) and there is no drip irrigation systems (DIS) used. 100 hectares of the irrigable area has sufficient natural drainage (NDS), 70 hectares have limited drainage (LDS), 20 hectares are artificially drained (ADS) and the remaining 10 hectares are waterlogged (WLS).

Table 4 Olierivier 1998 monthly average Eciw (mS/m)

\begin{tabular}{|c|c|c|c|c|c|c|c|c|c|c|c|}
\hline Jan & Feb & Mar & Apr & May & Jun & Jul & Aug & Sep & Oct & Nov & Dec \\
\hline 96 & 91 & 72 & 54 & 102 & 109 & 97 & 99 & 119 & 130 & 113 & 97 \\
\hline
\end{tabular}

Source: OVIB

The monthly average electrical conductivity of the irrigation water (ECiw), measured in milli-Siemens per meter $(\mathrm{mS} / \mathrm{m})$, is depicted in table 4 . The annual average of these monthly average ECiw values measured by OVIB through the year in 1998 (OL98) is $98.25 \mathrm{mS} / \mathrm{m}$ and is used in Table to set up a range of water qualities incrementally varied at positive and negative intervals of 10 per cent. This range of water qualities is broadened in a forthcoming WRC report on which this paper is based, where SALMOD is run for a range of predicted water qualities as determined by Du Preez et al., 2000: 18.

Table 5 The annual average ECiw varied prametrically from the 1998 OVIB reading for Olierivier

\begin{tabular}{|l|c|c|c|c|c|c|c|}
\hline & Mn3 & Mn2 & Mn1 & OL98 & PL1 & PL2 & PL3 \\
\hline Parametric range & $-30 \%$ & $-20 \%$ & $-10 \%$ & OL98 & $+10 \%$ & $+20 \%$ & $+30 \%$ \\
\hline $\begin{array}{l}\text { Annual Average } \\
\text { ECiw (mS/m) }\end{array}$ & 68.8 & 78.6 & 88.4 & 98.3 & 108.1 & 117.9 & 127.7 \\
\hline
\end{tabular}


Table 6 shows the change in TGMASC, water fine and return-flows over the parametric range of water quality variations. The dual values are zero because return-flows are not constrained.

Table 6 Percentage change in TGMASC (R), total fine (R) \& returnflows (mm) from the OVIB $1998 \mathrm{ECiw}$ results for a parametric run with no management options, Olierivier case study farm (2000)

\begin{tabular}{|l|r|r|r|r|r|r|r|}
\hline \multicolumn{7}{|c|}{ Parametric model run for: } \\
\hline & MN3 & MN2 & MN1 & EC98 & PL1 & PL2 & PL3 \\
\hline Total Gross & & & & & & & \\
Margin & $2.8 \%$ & $2.1 \%$ & $1.0 \%$ & R 908 278 & $-6.6 \%$ & $-14.2 \%$ & $-27.2 \%$ \\
\hline Total Water Fine & $0.0 \%$ & $0.0 \%$ & $0.0 \%$ & R 35 673 & $0.0 \%$ & $0.0 \%$ & $0.0 \%$ \\
\hline Return-flows & $-3.4 \%$ & $10.1 \%$ & $10.1 \%$ & $\mathbf{1 3 4 0 8 ~} \mathbf{~ m m}$ & $13.0 \%$ & $167.8 \%$ & $173.7 \%$ \\
\hline Dual & $0 \%$ & $0 \%$ & $0 \%$ & $\mathbf{0}$ & $0 \%$ & $0 \%$ & $0 \%$ \\
\hline
\end{tabular}

Table 7 shows the change in optimal crop composition over ECiw varied parametrically. Wheat replaces maize at EC98 but, interestingly enough, at EC98 + 20\% (PL2) maize replaces lucerne resulting in a 167.8 per cent increase in return-flows (Table 6) from the EC98 level. Using the Olierivier case study farmer's own CEBs, SALMOD is set up to choose only between wheat, maize, groundnuts, potato and lucerne.

Table 7 Optimal crop composition (hectares) for a parametric run with no management options using OVIB 1998 ECiw values as basis, Olierivier case-study farm (2000)

\begin{tabular}{|l|c|c|c|c|c|c|c|}
\hline \multicolumn{7}{|c|}{ Optimal crop composition } \\
\hline & MN3 & MN2 & MN1 & EC98 & PL1 & PL2 & PL3 \\
\hline Wheat & & & & $\mathbf{4 0 . 0}$ & 43.8 & 58.2 & 30.0 \\
\hline Maize & 43.0 & 46.2 & 46.2 & $\mathbf{1 . 0}$ & & 21.0 & \\
\hline Groundnut & & & & & & & \\
\hline Potato & 6.0 & 6.0 & 6.0 & $\mathbf{6 . 0}$ & 6.0 & 6.0 & 6.0 \\
\hline Lucerne & 141.0 & 137.8 & 137.8 & $\mathbf{1 4 3 . 0}$ & 140.2 & 104.8 & 130.4 \\
\hline
\end{tabular}

In Table 8 it can clearly be seen how the productive value of irrigation water decreases as the water quality deteriorates. In all water after-year fine rows (WF1-4) the shadow price decreases from left to right. For the pre-year water fine row (WFPY) this is also true except for column PL2 where maize is brought into the optimal crop composition again placing a higher potential value on pre-year water resulting in the deviation at PL2. In Table 8 the dual prices 
for extra irrigation water in both the pre- and after-years change significantly as water quality deteriorates.

Table 8 Change in water fine shadow values (R) from the OVIB 1998 ECiw results for a parametric run with no management options, Olierivier case-study farm, 2000

\begin{tabular}{|l|c|c|c|c|c|c|c|}
\hline \multicolumn{8}{|c|}{ Water fine shadow values } \\
\hline & MN3 & MN2 & MN1 & EC98 & PL1 & PL2 & PL3 \\
\hline WFPY & 1.83 & 1.66 & 1.69 & 1.70 & 0.94 & 1.58 & 0.47 \\
\hline WF1 & 2.58 & 2.41 & 2.43 & 2.45 & 1.69 & 1.66 & 1.21 \\
\hline WF2 & 2.49 & 2.32 & 2.35 & 2.36 & 1.60 & 1.57 & 1.13 \\
\hline WF3 & 2.41 & 2.24 & 2.26 & 2.28 & 1.52 & 1.49 & 1.04 \\
\hline WF4 & 2.32 & 2.15 & 2.18 & 2.19 & 1.43 & 1.40 & 0.96 \\
\hline
\end{tabular}

Figure 3 TGMASC for the Olierivier case-study farm using OVIB 1998 ECiw readings varied parametrically, with and without returnflows constrained and fixed capital management options implemented, 2000

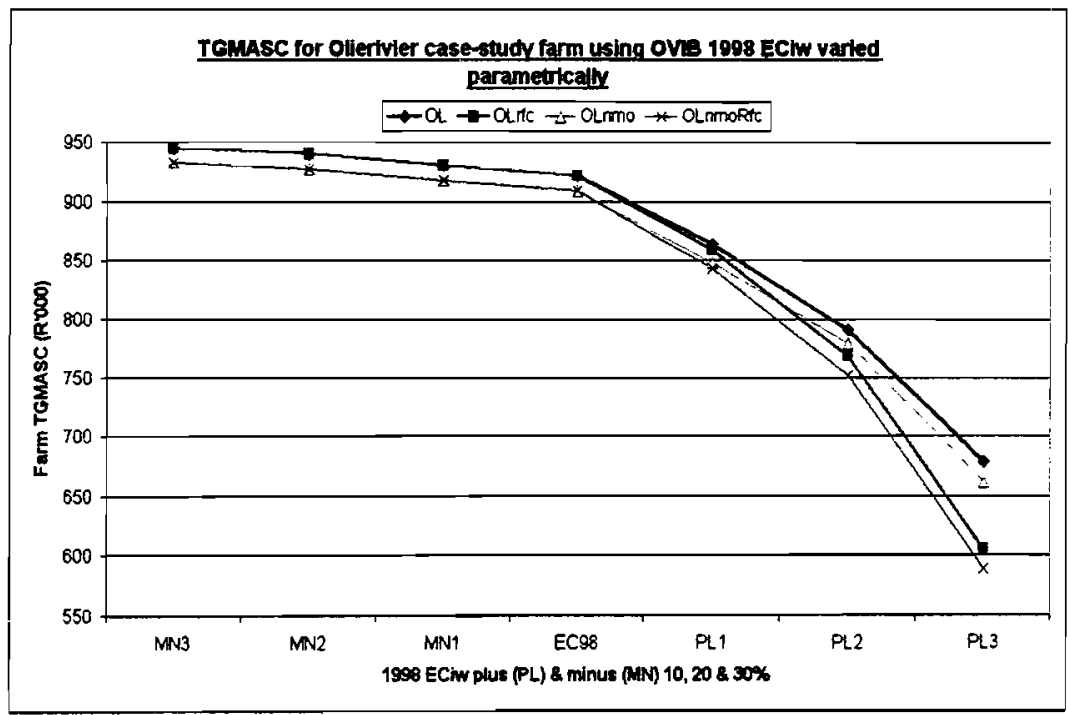

Figure 3 shows the maximum attainable TGMASC for the Olierivier case-study farm at the 1998 ECiw varied parametrically for various scenarios. If the irrigation water quality were to be improved by 10 to 30 per cent from the 1998 
ECiw average, constraining return-flows would have no effect as can be seen by the $\mathrm{OL}$ and Olrfc, and also the OLnmo and OLnmoRfc lines coinciding over MN3, MN2, MN1 and EC98. What this shows, is that if policy is implemented to constrain return-flows, water quality will be improved and prevented from deteriorating further. Under these improved water quality conditions, the retumflows from the resulting optimal crop composition will be less than the maximum specified in the constraint, making the return-flows constraint no longer necessary once farmers are using and managing their on-farm storage dams properly. However, farmers have to be convinced to install drainage and to build on-farm storage dams.

If water quality were to deteriorate form PL1 to PL3, TGMASC decreases substantially as can also be seen in Table 9 . For a water quality deterioration of 30 per cent, Table 9 shows a 35 per cent reduction from the attainable TGMASC modelled under 1998 ECiw conditions when no management options are implemented and return-flows are constrained (row OLnmoRfc and column PL3). A 25 per cent reduction in TGMASC is attainable at the same water quality conditions if return-flows are not constrained and management options implemented (row OL and column PL3). The impact of constraining irrigation return-flows only starts to have an effect once water quality deteriorates till below 1998 ECiw levels.

Table 9 TGMASC (R/farm) for parametrically changed 1998 ECiw values for the Olierivier case-study farmer, 2000

\begin{tabular}{|lccccccc|}
\hline & MN3 & MN2 & MN1 & EC98 & PL1 & PL2 & PL3 \\
\hline Ave.Annual & & & & & & & \\
ECiw (mS/m) & $\mathbf{6 8 . 6}$ & $\mathbf{7 8 . 4}$ & $\mathbf{8 8 . 2}$ & $\mathbf{9 8}$ & $\mathbf{1 0 7 . 8}$ & $\mathbf{1 1 7 . 6}$ & $\mathbf{1 2 7 . 4}$ \\
\hline OL & $4.0 \%$ & $3.5 \%$ & $2.4 \%$ & $1.4 \%$ & $-4.8 \%$ & $-12.9 \%$ & $-25.3 \%$ \\
\hline Olrfc & $4.0 \%$ & $3.5 \%$ & $2.4 \%$ & $1.4 \%$ & $-5.4 \%$ & $-15.5 \%$ & $-33.4 \%$ \\
\hline Olnmo & $2.8 \%$ & $2.1 \%$ & $1.0 \%$ & $\mathbf{R 9 0 8 2 7 8}$ & $-6.6 \%$ & $-14.2 \%$ & $-27.2 \%$ \\
\hline OlnmoRfc & $2.8 \%$ & $2.0 \%$ & $1.0 \%$ & $0.0 \%$ & $-7.1 \%$ & $-17.2 \%$ & $-35.2 \%$ \\
\hline
\end{tabular}

Table 10 The impact of fixed capital management options on artificial drainage installation (ha's) brought into the optimal solution for the Olierivier case-study farm using 1998 OVIB ECiw values, 2000

\begin{tabular}{|l|c|c|c|c|}
\hline Soil Trans.WL-AD & LMS & SNL & SNC & CLY \\
\hline FIS & 0 & 5 & 0 & 0 \\
\hline CPI & 0 & 5 & 0 & 0 \\
\hline
\end{tabular}


The management options determined by SALMOD to realise the optimal TGMASC for the 1998 ECiw scenario are shown in Table 10 SALMOD calculates that installing artificial drainage to convert 10 hectares of waterlogged sandy-loam soils, 5 of which are flood irrigated and 5 hectares under centre pivot, to fully artificially drained soils will bring about a 1.4 per cent (see Table 9, OL-98) increase in TGMASC after the annualised costs of this option are deducted.

Table 11 Water over use volumes, fines (Cost) and shadow price (Dual) results for the Olierivier case-study farm using 1998 OVIB ECiw data, 2000

\begin{tabular}{|l|c|c|c|}
\hline Stepped tariff & Volume (mm) & Cost (R) & Dual (R) \\
\hline WF1 & 14100 & 3596 & 2.4473 \\
\hline WF2 & 14100 & 4794 & 2.3623 \\
\hline WF3 & 14100 & 5993 & 2.2773 \\
\hline WF4 & 14100 & 7191 & 2.1923 \\
\hline WFPY & 14100 & 14100 & 1.7023 \\
\hline
\end{tabular}

Table 11 indicates that the volume of the irrigation quota is most constraining. At the current water price and stepped water overuse fine structure, all 4 levels of the after-year fine (WF1-4) and the full pre-year fine (WFPY) volumes are fully utilised. This is true for all incremental water quality scenarios that the model was run at for Olierivier. This is partially because more irrigable land is available ( $200 \mathrm{ha}$ 's) than water rights (141 ha's) to irrigate all the land with.

The dual of the first after-year fine tier (R2.45) indicates that for every 1 extra millimetre per hectare of water rights available at that specific charge rate ( $\mathrm{R} 0.17+\mathrm{R} 0.17 \times 50$ per cent per $\mathrm{mm} / \mathrm{ha}$ ), an extra $\mathrm{R} 2.45$ / ha would be added to the TGMASC. This indicates that for every 26.5 cents that the farmer currently pays for the $1^{\text {st }}$ tier of water overuse, he makes 244.7 cents, and thus indirectly could afford to pay up to 244.7 cents per millimetre per hectare for that water. As water quality however changes (see Table 8) the dual prices for irrigation water change quite markedly.

\section{The impact of changing the price of irrigation water for Olierivier}

Table 12 shows the change in the water fine rates as the water price is increased from $\mathrm{R} 0.17$ per $\mathrm{mm} / \mathrm{ha}$ to $\mathrm{R} 1.70$ per $\mathrm{mm} / \mathrm{ha}$. Water fines for overuse in the after-year are directly linked to the water price while in the dry pre-year the water overuse fine is fixed at R1.00 with the OVIB 2000 water pricing structure. The analysis in Table 13 based on this range of prices, includes the 
water fine for the pre-year (WFPY) at the fixed value of R1.00 per $\mathrm{mm} / \mathrm{ha}$ for all water prices. The shadow value of WFPY at the increased rate of R0.34 per $\mathrm{mm} / \mathrm{ha}$ is R1.92 indicating that it would not be feasible to use extra water in the pre-year at R2.00 per mm/ha as for each R2.00 spent for each $1 \mathrm{~mm} / \mathrm{ha}$ extra pre-year water TGMASC will only increase by R1.92.

Table 13 The water fine tariff structure for the OVIB in response to increases in the price of water

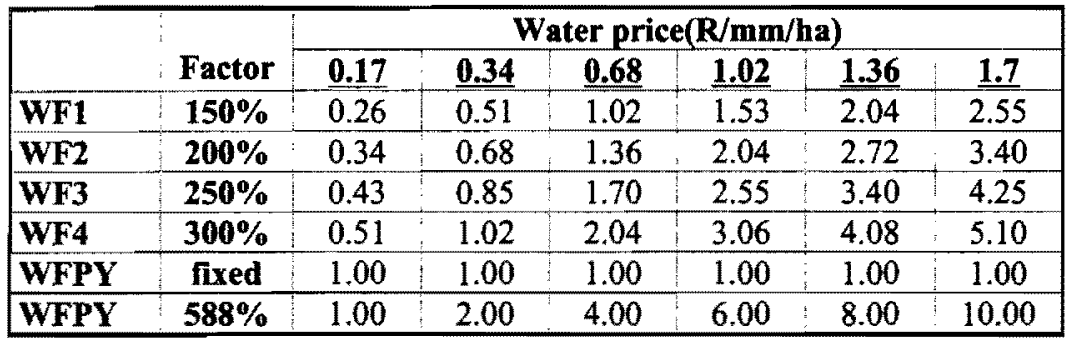

Table 13 shows the impact of increasing the price of irrigation water on TGMASC, water fine costs, return-flows, the optimal crop composition and the shadow prices of the water fines as the water price is increased from R0.17 per $\mathrm{mm} / \mathrm{ha}$ to $\mathrm{R} 1.70$ per $\mathrm{mm} / \mathrm{ha}$.

In Table 13 we see that at the full volume of pre-year extra water allowed, subject to the pre-year water fine (WFPY), remains fully utilised as the water price is increased (indicated by positive shadow values) because the pre-year water fine is not linked to the water price, as are the after-year stepped fines. Negative after-year water fine shadow values show the decrease in the fine water price needed before that tier of water can be used profitably on the farm.

As water quota costs and water overuse fine costs are included as production costs in SALMOD, it was found in the farm-level results (not shown in this report) that the increasing cost of water causes production capital to become constraining.

Increasing the price of irrigation water results in less retum-flows, but only after a 6-fold increase in the cost of irrigation water, at which rate all the extra water is no longer viable to use to leach. Increasing the price of irrigation water is therefore not a sustainable irrigation policy to reduce the agricultural returnflows as it provides an incentive not to leach that will lead to the building up of salts in the vadose zone. 
Table 13 The impact of a change in irrigation water prices on TGMASC, total excess water use fine, return-flows, crop composition and water fine shadow values for 1998 OVIB ECiw data for the Olierivier case-study farm, 2000

\begin{tabular}{|l|c|c|c|c|c|c|}
\hline $\begin{array}{c}\text { Water price } \\
\text { (R/mm/ha) }\end{array}$ & $\mathbf{0 . 1 7}$ & $\mathbf{0 . 3 4}$ & $\mathbf{0 . 6 8}$ & 1.02 & $\mathbf{1 . 3 6}$ & $\mathbf{1 . 7 0}$ \\
\hline Total Gross Margin (R) & 964272 & 916557 & 815092 & 727246 & 671133 & 630436 \\
\hline Total Water Fine (R) & 35673 & 57246 & 100392 & 64437 & 14100 & 14100 \\
\hline Return-flows (mm/ha) & 11139 & 11139 & 11139 & 9729 & 8319 & 8319 \\
\hline & Optimal crop composition (ha) & & \\
\hline Wheat & 25.42 & 13.29 & 0 & 0 & 0 & 0 \\
\hline Maize & 91.54 & 77.49 & $\mathbf{3 4 . 8 8}$ & 52.59 & 87.85 & 65.34 \\
\hline Groundnut & 0 & 0 & 0 & 0 & 0 & 0 \\
\hline Potato & 6.00 & 6.00 & 6.00 & 6.00 & 6.00 & 6.00 \\
\hline Cotton & 0 & 0 & 0 & 0 & 0 & 0 \\
\hline Lucerne & 102.46 & 116.51 & 146.9 & 116.05 & 75.51 & 87.92 \\
\hline & Water fine shadow values (r) & & \\
\hline WFPY & 2.03 & 1.92 & 1.78 & 1.54 & 1.30 & 1.06 \\
\hline WF1 & 2.85 & 2.47 & 1.75 & 0.87 & -0.02 & -0.90 \\
\hline WF2 & 2.76 & 2.28 & 1.32 & 0.22 & -0.88 & -1.97 \\
\hline WF3 & 2.67 & 2.09 & 0.89 & -0.42 & -1.73 & -3.05 \\
\hline WF4 & 2.57 & 1.90 & 0.47 & -1.06 & -2.59 & -4.12 \\
\hline
\end{tabular}

\section{CONCLUSIONS}

What the automatic leaching fraction and yield percentage management option results show are that at current water prices, the economic impact of accepting a reduction in yield is greater than the cost of applying extra water to leach accumulated salts from the soil to attain a better yield. At current water prices SALMOD results indicate that the maximum yield is selected with as much leaching as required subject to the drainage status constraint of the specific soil. The results clearly show that the benefits form leaching more as water quality deteriorates, to obtain a 100 per cent yield, outweigh the costs of leaching until return-flows become constraining.

It is also clear form the results that where irrigation rights exceed irrigable area, irrigation water quantity is generally sufficient and the shadow prices of water overuse fines are generally lower than where irrigable area far exceeds irrigation rights. Furthermore, even with the high electricity costs of pumping irrigation water, SALMOD results show that the productive value of the extra water far exceeds the stepped fines charged for exceeding water quota allocations. 
When conducting the farm level survey, the impression gained was that where the irrigable area far exceeded the irrigation quota, it was a cheaper alternative to move the irrigation system to new land than to remediate old land. Irrigable land without water rights can be purchased for R7000 per hectare while the cost of installing artificial drainage could exceed R15000 per hectare. The purchase of additional land was however not an option included in the model. This practice is however unsustainable and very environmentally unfriendly.

The subsidisation of the costs of artificial drainage on farms (implemented in SALMOD by leaving the costs of drainage installation out of the objective function and production capital constraints), results in an increase in the volumes of return flows when return-flow volumes aren't constrained, which could actually further exacerbate the water quality problem. Subsidising irrigation drainage thus has to be implemented together with return-flow constraining/effective management policy.

By implementing policy constraining return-flows, water quality will be improved and prevented from deteriorating further. Under these improved water qualities the return-flows of the resulting optimal crop composition will be less than the maximum specified in the constraint, making the return-flows constraint no longer necessary once farmers are using and managing their onfarm storage dams properly, but are initially required to get farmers to install drainage and build on-farm storage dams.

The scenario runs also show that when production capital is constraining or limited, the capital will rather be used for production inputs than for implementing long-term capital improvements.

Maize and potato have the same sensitivity and gradient and are the most sensitive crops to salinity of the 6 included in SALMOD. Potatoes being by far the highest value crop are included for all water quality situations and take up the ideal soils leaving little room for maize. Maize requires large leaching fractions, so if water quota is constraining and well-leached soil is still available after potatoes have been included, other crops are brought into the optimal crop composition instead of maize.

The shadow prices of the stepped water overuse fines indicate how much a farmer could pay for water if a water market in which water rights could be freely traded existed. For the Olierivier farmer for example, only at eight times the current price of irrigation water is it no longer feasible to use extra irrigation water at a stepped fine rate. 


\section{FURTHER RESEARCH NEEDS}

By understanding the full dynamics and interactions between irrigation water quality and the soil salinity status on crop yield over irrigated time, mistakes made in the past by choosing unsustainable irrigation sites can be prevented. Furthermore the impact of various natural or artificial (e.g. policy mechanism) scenarios on existing schemes could be more accurately modelled, leading to increased economic efficiency and sustainability of the irrigation industry as a whole. However, current USDA Salinity Laboratory evidence suggests these interactions are far more complex than originally thought.

.... Rhoades, the doyen of soil/plant/salinity interactions, contends that no one has succeeded in combining all the refinements necessary to overcome the inherent problems of relatively simple salt balance models and geophysical sensors, to address the enormous field variability of infiltration and leaching rates (Blackwell et al., 2000).

Current literature and research on salinity management in irrigation agriculture also fails to capture the stochastic nature of inter-seasonal irrigation water quality as well as the cumulative economic and sustainability effects of irrigating with stochastic water quality levels.

Further limitations for setting criteria for salinity include: (i) the need to make assumptions about the relationship between soil saturation extract salinity (for which yield response data is available) and soil solution salinity. (ii) the deviation of the salinity of the soil saturation extract from the mean soil profile salinity, to which crops would respond. (iii) The criteria for crop salt tolerance do not consider differences in crop tolerance during different growth stages (DWAF, 1996).

\section{ENDNOTE}

This paper is based on preliminary findings of a current Water Research Commission (WRC) project due for completion by the end of 2001. Financial support from the WRC to enable this research, and from USAID to attend this conference is hereby acknowledged. 


\section{REFERENCES}

1 ARMOUR, R.J. \& VILJOEN, M.F. (forthcoming) "The Economic Impact of Changing Water Quality on Irrigated Agriculture in the Lower Vaal and Riet Rivers", WRC Report No. 947/1/01, Pretoria.

2 ASCE (1990) Agricultural Salinity Assessment and Management, Manuals and Reports on Engineering Practice No. 71. TANJ, K.K. (ed.) American Society of Civil Engineers: NY.

3 AYERS, R.S. \& WESTCOT, D.W. (1985) Water Quality for Agriculture, FAO Irrigation and Drainage Paper 29, Rev. 1: Rome.

4 BACKEBERG, G.R. BEMBRIDGE, T.J., BENNIE, A.T.P., GROENEWALD, J.A., HAMMES, P.S., PULLEN, R.A. \& THOMPSON, H. (1996) Policy Proposal for Irrigated Agriculture in South Africa. Discussion paper July 1996, WRC. Report No. KV96/96. Beria Printers: Pretoria.

5 BASSON, M. S., van Niekerk, P.H. \& Van Rooyen, J.A. (1997) Overview of the Water Resources Availability and Utilisation in South Africa. Department of Water Affairs and Forestry Report P RSA/00/0197, Cape Town: CTP Book Printers.

6 BROOK, A., KENDRICK, D., MEERAUS, A. \& RAMAN, R. (1997) GAMS Release 2.25 Version 92 Language Guide. GAMS Development Corporation, Washington DC.

7 BLACKWELL, J., BISWAS, T.K., JAYAWARDANE, N.S. \& TOWNSEND, J.T. (2000) Irrigation - Getting the Edge. CSIRO Land and Water, PMB No 3, Griffith, NSW

8 BRADY, N.C. \& WEIL, R.R. (1996) The Nature and Properties of Soils, 11 th ed., Prentice Hall International Editions, New Jersey.

9 DU PLESSIS, H.M. (1982) "Die Uitwerking van Verswakkende Waterkwaliteit op die Opbrengs van Gewasse Langs die BenedeVaalrivier", Department of Agriculture. Confidential Report No. 987/174/82. Research Institute for Soil and Irrigation, Pretoria.

10 DU PREEZ, C.C., STRYDOM, M.G., LE ROUX, P.A.L., PRETORIUS, J.P., VAN RENSBURG. L.D. \& BENNIE, A.T.P. (2000) "Effects of Water Quality on Irrigation Farming Along the Lower Vaal River: The Influence on Soils an Crops", WRC Report No. 740/1/00, Pretoria.

11 DWAF (Department of Water Affairs and Forestry) (1993) "South African Water Quality Guidelines" (1st ed.) Vol. 4: Agricultural use. The Government Printer: Pretoria

12 FRANCOIS \& MAAS, E.V. (1994) "Crop Response and management on Salt-Effected Soils" In: M. Pessarakli (ed.) Handbook of Plant and Crop Stress, Marcel Dekker, Inc.: NY.

13 GOUWS, J.A., NEL, P. \& BROODRYK, S.W. (1998) "Quantifying the Impact of Salinisation of South Africa's Water Resources with Special 
Reference to Economic Effects", vol. 3: Agricultural sector. Draft document for the WRC by Urban Econ.

14 KIJNE, J.W., PRATHAPAR, S.A, WOPEREIS, M.C.S. \& SAHRAWAT, K.L. (1998) "How to Manage Salinity in Irrigated Lands: A Selective Review with Particular Reference to Irrigation in Developing Countries", SWIM Paper 2, International Irrigation Management Institute. Sri Lanka.

15 MAAS, E.V. \& HOFFMAN, G.J. (1977) "Crop Salt Tolerance - Current Assessment", ASCE Journal of Irrigation and Drainage. Div.103(IR2): 115-134.

16 McCARL, B.A. (1998) GAMSCHK Version 1.3 Developed by Dr.Bruce McCarl, mccarl@tamu.edu, Texas A\&M University.

17 MOOLMAN, J. \& QUIBELL, G. (1995) "Salinity Problems at the Douglas Weir and Lower Riet River", Institute for Water Quality Studies - DWAF. Report Number N/C900/29/DIQ1495.

18 NEGAHBAN, B., MOSS C.B., JONES, J.W., ZANG, J., BOGGESS, W.D. \& CAMPBELL, K.L. (1996) "Optimal Field Management for Regional Water Quality Planning", 3rd International Conference/ Workshop on Integrating GIS and Environmental Modeling. January 2125, Santa Fe, New Mexico.

19 NEL, J.P. (1995) "Kriteria vir Besproeingswater van Gronde in die Rietrivier en Laer Vaalrivier wat deur die Oranje-Rietkanaal Bedien Word", Instituut vir Grond, Klimaat en Water, Verslag Nr. GW/A/95/5.

20 RHOADES, J.D., KANDIAH, A. MASHALI, A.M. (1992) "The Use of Saline Waters for Crop Production", FAO Irrigation and Drainage Paper 48: Rome.

21 SECKLER, D., BARKER, R. \& AMARASINGHE, U. (1999) "Water Scarcity in the Twenty-first Century", International Journal of Water Resources Development Vol: 15 No: 1 Page: 29 - 42. Carfax publishers. 